könnte; der staatliche Zugriff läuft parallel zu dem bei der herkömmlichen Patientendokumentation. Dieses Ergebnis folgt jedoch nicht aus dem unmittelbaren Wortlaut des Gesetzes, sondern muss über eine Analogie des \$ 97 Abs. 2 S. 1 Halbs. 2 StPO hergeleitet werden. Nur so kann das verfassungsrechtlich gewährleistete Vertrauensverhältnis zwischen Patienten und Leistungserbringern, also insbesondere Ärzten, hinreichend geschützt und das gesetzgeberische Ziel, dieses durch das PDSG zu stärken, erreicht werden. Im Interesse der Rechtssicherheit ist erforderlich, dass der Gesetzgeber $₫ 97$ StPO entsprechend anpasst.

Sollte es doch einmal zur Beschlagnahme einer ePA kommen, gelten die allgemeinen Grundsätze zur Beweisverwertung. Erlangte Informationen sind nicht pauschal unverwertbar, es sei denn, es liegt ein Eingriff in die Intimsphäre des Versicherten vor. Nicht jede Information in der Krankenakte betrifft jedoch die Intimsphäre, in der Regel ist ,nur" die Privatsphäre betroffen. Soweit die Privatsphäre betroffen ist, ist abzuwägen zwischen dem allgemeinen Persönlichkeitsrecht des Versicherten einerseits und Strafverfolgungsinteresse des Staates andererseits. Dabei ist jedoch zu berücksichtigen, dass die Eingriffsintensität bei der Beschlagnahme einer ePA je nach Ausmaß ihrer Befüllung höher sein kann als bei einer herkömmlichen Dokumentation. Im Übrigen überwiegt das Interesse des Versicherten an der Wahrung seiner Rechte das staatliche Strafverfolgungsinteresse, wenn die ePA trotz Beschlagnahmeverbots beschlagnahmt wurde.

\title{
https://doi.org/10.1007/s00350-021-5977-9
}

\section{Hirnorganoide - Ethische Herausforderungen und ihre Berücksichtigung und Umsetzung im Recht}

\author{
Anna Kunz und Hannes Wolff
}

\begin{abstract}
Die Forschung an Organoiden wird zu einem immer intensiver diskutierten Thema, insbesondere in Ethik und Recht. Das gilt insbesondere auch für Hirnorganoide. Für sie ist denkbar, dass sie eines Tages in der Lage sein könnten, höhere Bewusstseinszustände zu erlangen. In diesem Fall wären sie (anders als Organoide anderer Körperteile) möglicherweise besonders schutzwürdig und könnten deshalb einer besonderen gesetzlichen Regelung bedürfen. Der folgende Aufsatz analysiert die sich hinsichtlich solcher höherentwickelten Hirnorganoide auftretenden ethischen und rechtlichen Probleme. Er zeigt auf, dass eine Reihe von Konzepten, an die eine gesetzliche Regelung anknüpfen könnte, schon an anderer Stelle Eingang in das geltende Recht gefunden haben. Diese im folgenden vorgestellten Regelungsansätze könnten einem für höherentwickelte Hirnorganoide möglicherweise zu schaffenden Gesetz zugrunde gelegt werden. Zudem wird eine Handlungsempfehlung für die Übergangszeit bis zum etwaigen Erlass einer solchen Regelung angeboten.

Jedes neue Feld medizinischer und naturwissenschaftlicher Forschung birgt das Potential, Gegenstand öffentlicher Debatten zu sein. Das gilt umso mehr, wenn (auch) am
\end{abstract}

Hannes Wolff, wissenschaftlicher Mitarbeiter und Doktorand am Lehrstuhl für Staats- und Verwaltungsrecht, Völkerrecht, Internationales und Europäisches Wirtschaftsrecht

von Prof. Dr. iur. Hans-Georg Dederer an der Universität Passau

Innstraße 39, JUR 102, 94032 Passau, Deutschland

Anna Kunz, studentische Hilfskraft am Lehrstuhl für Staats- und Verwaltungsrecht, Völkerrecht,

Internationales und Europäisches Wirtschaftsrecht

von Prof. Dr. iur. Hans-Georg Dederer

an der Universität Passau.

Innstraße 39, JUR 102, 94032 Passau, Deutschland

Gefördert vom Bayerischen Staatsministerium für Wissenschaft und Kunst im Rahmen des Bayerischen Forschungsverbundes „ForInter - Interaktion humaner Gehirnzellen“"

Wir danken Herrn Prof. Dederer für wertvolle Kommentare und Anmerkungen.
Menschen geforscht wird und deshalb ethische Konflikte, wie die Frage nach der Schutzwürdigkeit einer Entität durch das Erlangen eines Bewusstseinszustands, auftreten können.

In diesem Lichte soll das noch relativ neue Forschungsfeld der zerebralen Organoide, auch bekannt unter der Bezeichnung Hirnorganoide, betrachtet werden. Nach einer Einführung in den naturwissenschaftlichen Forschungsstand (I.) werden die ethischen Konflikte zusammengetragen, die sich in Bezug auf Hirnorganoide ergeben (II.). In früheren Debatten ist eine Reihe der Fragen, die sich auch in Bezug auf Hirnorganoide stellen, bereits diskutiert worden. Wir prüfen, inwiefern sich die Antworten auf diese Fragen auf die ethisch-rechtliche Diskussion um Hirnorganoide übertragen lassen (III.). Zusätzlich wird ein Handlungsvorschlag entwickelt, der eine Empfehlung für das weitere Vorgehen auf diesem Forschungsgebiet bis zu einer eindeutigen rechtlichen Regelung ausspricht (IV.).

\section{Einführung in den aktuellen naturwissenschaftlichen Forschungsstand}

\section{Die Entwicklung zerebraler Organoide}

Organoide sind aus Stammzellen ${ }^{1}$ generierte dreidimensionale Zellgebilde, die durch die in ihnen vorhandenen Zellen und deren räumliche Organisation ein in vivo vorhandenes Organ nachbilden und grundlegende Funktionen des abgebildeten Organs widerspiegeln.

Im Jahr 2013 gelang es Forschern um Madeline Lancaster zum ersten Mal, aus iPSZ dreidimensionale Hirnorga-

1) Für die Herstellung von zerebralen Organoiden wird auf induzierte pluripotente Stammzellen (iPSZ) zurückgegriffen. Sie unterscheiden sich von den früher nur vorhandenen humanen embryonalen Stammzellen (hESZ) dadurch, dass für ihre Gewinnung keine Zerstörung von Embryonen erforderlich ist. Für ihre Herstellung werden einem Menschen entnommene somatische Körperzellen entdifferenziert und können dann entweder direkt als iPSZ weiterverwendet oder zu einem bestimmten Zelltyp reprogrammiert werden. Zur historischen Entwicklung von iPSZ seit Mitte des 19. Jahrhunderts ausführlich Faltus, Stammzellenreprogrammierung, 2016, $130 \mathrm{ff}$. 
noidkulturen zu entwickeln. Diese Hirnorganoide hatten untereinander abhängige, aber klar voneinander getrennte, eindeutig identifizierbare Hirnregionen ausgebildet ${ }^{2}$. Während ihrer Entwicklung zeichnen zerebrale Organoide die Entwicklung menschlicher Gehirne in vivo nach ${ }^{3}$ - die beobachteten Entwicklungsprozesse und biologischen Vorgänge lassen sich in ähnlicher Form in menschlichen Embryonen etwa bis zum Ende des zweiten Schwangerschaftsdrittels beobachten ${ }^{4}$. Allerdings werden nicht alle in menschlichen Gehirnen vorhandenen Zelltypen ausgebildet und eine komplexe Verschaltung der Hirnregionen hat sich bisher ebenfalls nicht nachweisen lassen ${ }^{5}$. Bislang ist die Entwicklung der Organoide zudem in ihrer Größe stark begrenzt. Die „Mini-Gehirne“ konnten mangels eines eigenen Blutgefäßsystems nur wenige Millimeter groß werden $^{6}$. Forscher:innen an der Universität Yale ist es nun jedoch gelungen, Organoide nicht nur nach der Einpflanzung in Mäuse, also letztlich in vivo, ,nachträglich“ mit einem Gefäßsystem zu versehen ${ }^{7}$, sondern Organoide auch in vitro mit einem eigenen blutgefäßähnlichen System zu züchten $^{8}$. Zu den bisher ausgebildeten Zelltypen gehören auch Retinazellen. Verschiedene Versuche haben gezeigt, dass die gezüchteten Organoide photosensitiv sind, also auf Lichtreize ,reagieren“9. Welcher Natur diese Reaktion ist, konnte bisher aber noch nicht geklärt werden. Die elektrische Aktivität in Hirnorganoiden wurde an anderer Stelle bereits mit derjenigen von frühgeborenen Säuglingen verglichen ${ }^{10}$. Im September 2020 berichtete Nature Communications erstmals über die „Lernfähigkeit“ von Organoiden, die sich nicht nur in einer Ausbildung erster Anzeichen neuronaler Netze zeigt, sondern auch in Anzeichen sog. „,neuronaler Plastizität“, also einer Anpassung der messbaren Aktivitäten an wiederholt eingespielte Reize ${ }^{11}$. Jedenfalls theoretisch scheinen ihrer Entwicklung damit keine Grenzen gesetzt zu sein ${ }^{12}$. Hirnorganoide, wie sie derzeit entwickelt werden können, sind noch weit davon entfernt, tatsächlich Bewusstsein ${ }^{13}$ auszubilden ${ }^{14}$. Während sie sich in ihren gegenwärtig erreichbaren Entwicklungsstadien daher nicht von sonstigem Gewebe unterscheiden - und auch rechtlich nicht anders zu behandeln sind ${ }^{15}$ - ist wichtig, sich vor Augen zu führen, dass die Anlagen für die mögliche Ausbildung solcher Bewusstseinsfunktionen bereits geschaffen sind und die Forschung erste Schritte in diese Richtung unternommen hat.

\section{Verwendungsmöglichkeiten zerebraler Organoide}

Zerebrale Organoide bieten vielfältige Verwendungsmöglichkeiten, u.a. die Untersuchung der Entwicklung des menschlichen Hirns ,am lebenden Objekt", die Erforschung komplizierter Krankheitsbilder ${ }^{16}$ und die Erprobung von Medikamenten an menschlichem und ggf. sogar patient:inneneigenem Gewebe oder „Organen“"17. Erklärtes Fernziel ist auch, beschädigtes Hirngewebe mit solch künstlich erzeugtem Hirngewebe zu ersetzen ${ }^{18}$.

\section{Das Zentralproblem: Bildung und Nachweis von Bewusstsein}

Insbesondere die Photosensitivität einiger Organoide wird als Hinweis darauf verstanden, dass die Möglichkeit der Bewusstseinsentwicklung bei Hirnorganoiden nicht völlig ausgeschlossen werden kann. Nimmt man an, dass mögliche künftige Regelungen an das Vorhandensein von Bewusstsein anknüpfen, stellt sich nicht nur das Problem eines Nachweises von Bewusstsein als solchem. Vielmehr muss Bewusstsein auch - abseits von einem binären Nachweissystem - quantifiziert werden können, um eine verlässliche Grenzziehung zwischen der Anwendbarkeit und Nichtanwendbarkeit von Regelungen zu ermöglichen, die an das Vorhandensein eines bestimmten Maßes an Bewusstsein anknüpfen.
Derzeit gibt es allerdings noch keine verlässliche Methode zum Nachweis von Bewusstsein, die nicht auf eine Interaktion der zu untersuchenden Entität mit ihrer Umwelt angewiesen ist. Lavazza und Massimini haben 2018 vorgeschlagen ${ }^{19}$, für die Messung auf die Ideen der von Tononi geprägten Integrated Information Theory of Consciousness (IIT) ${ }^{20}$ und den auf deren Grundlage von Casali et al. entwickelten Perturbational Complexity Index (PCI $)^{21} \mathrm{zu}-$ rückzugreifen. Die IIT, nach der sich die Fähigkeit zum Erleben aus der optimalen Balance zwischen Information

2) Lancaster/Renner/Martin u.a., Nature 2013, $373 \mathrm{ff}$;; Quadrato/ Nguyen/Macosko u.a., Nature 2017, 48; Qian/Nguyen/Song u.a., Cell 2016, 1238; Paşca/Sloan/Clarke u.a., Nature Methods 2015, 671.

3) Pașca, Nature 2018, 437, 441.

4) Velasco/Kedaigle/Simmons u. a., Nature 2019, $523 \mathrm{ff}$.; Chen/Song/ Ming, Developmental Dynamics 2019, 53, 58.

5) Chen/Wolf/Blue u.a., Cell Stem cell 2019, 462, 464.

6) Kadoshima/Sakaguchi/Nakano u. a., PNAS 2013, 20284; Lancaster/ Corsini/Wolfinger u.a., Nature Biotechnology 2017, 659; Qian/ Nguyen/Song u. a., Cell 2016, 1238; neurale Vorläuferzellen mit großem Sauerstoff- und Nährstoffbedarf siedeln sich vornehmlich im Inneren des Hirnorganoids an. Wegen der schlechten Sauerstoff- und Nährstoffversorgung bildet sich ein die weitere Entwicklung behindernder nekroser Kern (vgl. Chen/Wolf/Blue u. a., Cell Stem cell 2019, 462). Lee/Bendriem/Wu u. a., J Biomed Sci 2017, 59; ebenfalls Wimmer/Leopoldi/Aichinger u.a., Nature 2019, 505, die erfolgreich Gefäßorganoide gezüchtet haben.

7) Mansour/Gonçalves/Bloyd u.a., Nature Biotechnology 2018, 432; Daviaud/Friedel/Zou, eNeuro.0219-18.2018.

8) Cakir/Xiang/Tanaka u.a., Nature Methods 2019, 1169.

9) Quadrato/Nguyen/Macosko u. a., Nature 2017, 48.

10) Trujillo/Gao/Negraes u.a., Cell Stem Cell 2019, 558, 563. Dafür wurde auf bestehende Datensätze von Frühgeborenen im Alter zwischen 24 und 38 Wochen p.c. (post conceptionem) zurückgegriffen. Nicht geklärt ist, ob sich die Aktivität gleicht oder lediglich ähnelt, ob sie also tatsächlich ein Hinweis auf das Vorliegen von Bewusstsein oder eines Potentials für Bewusstsein ist. Bisher konnten die Ergebnisse dieser Versuchsreihe in anderen Laboren nicht reproduziert werden.

11) Zafeiriou/Bao/Hudson u.a., Nat Commun 2020, 435; vgl. auch Podbregar, Hirn-Organoid mit lernfähigem Netzwerk, www. wissenschaft.de, Zugriff am 21.7.2021.

12) Jedenfalls in vivo im Vergleich zu den in vitro Organoiden nur geringes oder kein messbares Zellsterben: vgl. Mansour/Gonçalves/ Bloyd u. a., Nature Biotechnology 2018, 432.

13) $\mathrm{Zu}$ den unterschiedlichen Arten und Stufen von Bewusstsein s. II. 2. b)-d).

14) Darüber sind sich Naturwissenschaft und Ethik einig, vgl. exemplarisch Reardon, Nature 2020, 658, 659; Koch, The feeling of life itself, 2019, 126 ff., 201; Chen/Song/Ming, Developmental Dynamics 2019, 53, 59.

15) Der vorliegende Aufsatz behandelt daher die möglicherweise zukünftig verfügbaren Hirnorganoide, die in der Lage sind höhere Bewusstseinsfunktionen zu erlangen.

16) Quadrato/Brown/Arlotta, Nature Medicine 2016, 1220 (Neuropsychiatrische Erkrankungen); Gerakis/Hetz, Molecular Psychiatry 2019, 474 (Alzheimer); Lancaster/Renner/Martin u.a., Nature 2013, 373 (Mikroenzephalie); Stachowiak/Benson/Narla u.a., Translational Psychiatry 2017, 6 (Schizophrenie); Qian/Nguyen/ Song u.a., Cell 2016, 1238 (Zika-Virus); Zhang/Chu/Han u.a., Cell Research 2020, 928 (SARS-CoV-2).

17) Paşca, Nature 2018, 437, 442; Chuye/Dimitri/Desai u.a., in: Buzanska, Human Neural Stem Cells, 2018, S. 183 ff., S. 199, auch Vorschlag der Einführung einer „Phase 0“ bei vorklinischen Medikamentenstudien, noch vor den Tierversuchen. Ggf. können auf diesem Weg auch die üblicherweise erforderlichen klinischen Versuche neuer Medikamente am Menschen ersetzt oder jedenfalls sicherer gemacht werden. Vgl. Hostiuc/Rusu/Negoi u. a., Regenerative Therapy 2019, 118, $119 \mathrm{f}$.

18) Chen/Song/Ming, Dev Dyn 2018, 53, 54, 58; Chen/Jgamadze/Serruya u. a., Front Syst Neurosci 2018, 10:1.

19) Lavazza/Massimini, JME 2018, 606

20) Tononi/Sporns, BMC Neuroscience 2003; Tononi, BMC Neuroscience 2004, 42; Tononi, Scholarpedia 2015, 4164.

21) Casali/Gosseries/Rosanova u. a., Sci Transl Med 2013, 198ra105. 
und Integration ergibt ${ }^{22}$, scheint aus zwei Gründen relevant für Hirnorganoide zu sein: Sie beschreibt ausdrücklich, dass (1) Bewusstsein zwischen unterschiedlichen Entitäten abgestuft werden und (2) Bewusstsein unabhängig von sensorischer Verarbeitung oder motorischem Verhalten hervorgerufen werden bzw. vorhanden sein $\mathrm{kann}^{23}$. Mithilfe des PCI kann die vorhandene „Menge“ an Bewusstsein numerisch quantifiziert werden. Shepherd hat in Reaktion auf den theoretischen Ansatz von Lavazza/Massimini vorgeschlagen, sich stattdessen auf aus der menschlichen Entwicklung bekannte und daher greifbarere biologische Strukturen und neurale Signaturen zu konzentrieren, die erfahrungsgemäß nötig sind, damit überhaupt Bewusstsein und - zu einem späteren Zeitpunkt - höherrangige Bewusstseinsebenen entstehen können ${ }^{24}$. Messreihen an Menschen mit unterschiedlichen, auch pathologischen Bewusstseinszuständen haben eine grundsätzliche Eignung des PCI für die Abstufung von Bewusstsein gezeigt. $\mathrm{Ob}$ die Erkenntnisse auf die Feststellung oder Quantifizierung von Bewusstsein in Organoiden ohne Weiteres übertragbar sind, lässt sich zum derzeitigen Zeitpunkt allerdings noch nicht sagen ${ }^{25}$.

\section{II. Überblick über die ethischen Problemstellungen}

\section{Können Hirnorganoide selbst denken?}

Ob Hirnorganoide schon deshalb selbst denken können, weil sie aus Hirnzellen erschaffen sind, lässt sich schnell verneinen. Wie bereits oben aufgezeigt, zeichnen Hirnorganoide zwar die Entwicklung des menschlichen Gehirns nach und bilden die typischen Zelltypen und Hirnregionen aus, höherrangige Hirnfunktionen konnten aber noch nicht nachgewiesen werden. Hirnorganoide können bislang weder In- noch Output verarbeiten, was unter anderem auch dazu beiträgt, dass sie, im Vergleich zu höher entwickelten Lebewesen, höhere Bewusstseinsebenen (noch) nicht erreichen können ${ }^{26}$.

\section{Können Hirnorganoide Bewusstsein ausbilden?}

Zunächst muss festgelegt werden, was der Begriff „Bewusstsein" umfasst und welche Aspekte davon für die Forschung an Hirnorganoiden relevant sind. Eine allgemein akzeptierte Definition des Begriffs existiert nicht. Unter Bewusstsein wird aber meist die Fähigkeit zur Empfindung etwa von Vergnügen oder Schmerz ${ }^{27}$, sowie das Speichern und Abrufen von Erinnerungen und das Bewusstsein-übersich-selbst verstanden ${ }^{28}$. Dieses Verständnis findet auch hier Anwendung.

Mit steigender Komplexität der Entität gibt es verschiedene Grade des Bewusstseins ${ }^{29}$, die einer numerischen Quantifizierung grundsätzlich zugänglich sind (s.o., I.3.). Höherrangige Lebewesen zeichnen sich durch eine höhere Ausprägung der genannten Kriterien aus. Folglich kann sich Bewusstsein allerdings, z. B. bei Menschen mit Alzheimer oder in einem dauerhaften vegetativen Zustand, auch verringern ${ }^{30}$. Für die Zuerkennung unterschiedlicher Grade von Bewusstsein in nichtmenschlichen Entitäten greift die Ethik häufig auf bestimmte allgemeine Kriterien zurück, die im Folgenden aufgezeigt werden (a.). AnschlieBend wird auf Theorien unterschiedlicher Bewusstseinsausprägungen und deren Anwendbarkeit auf Hirnorganoide eingegangen (b. - d.).

a) Kriterien des Bewusstseins

Auch wenn bislang keine Einigkeit über die Definition von Bewusstsein herrscht ${ }^{31}$, werden als Kriterien hierfür in der Literatur vornehmlich die Empfindung von Schmerzen (aa.), die allgemeine Wahrnehmungsfähigkeit (bb.) und die allgemeine Leidensfähigkeit (cc.) genannt. aa) Schmerzempfinden

Das in der Literatur häufig vorgeschlagene Kriterium der Fähigkeit zur Empfindung physischer Schmerzen ${ }^{32}$ ist hinsichtlich zerebraler Organoide relativ unbedeutend, da diese keine Schmerzrezeptoren ausbilden und dementsprechend nicht anfällig für Schmerzen sind ${ }^{33}$.

bb) Wahrnehmungsfähigkeit

Auf die Fähigkeit zur Wahrnehmung der Außenwelt wird vor allem in der Abtreibungsdebatte abgestellt. Dabei wird Embryonen schon ab der 20. Woche p.c. die Möglichkeit einer Empfindungsfähigkeit zugesprochen, eine Ausprägung mit der Intensität eines Bewusstseins aber erst ab der 25. Woche p.c. angenommen ${ }^{34}$.

Konsequenterweise müsste man davon ausgehen, dass zerebrale Organoide eine Wahrnehmungsfähigkeit erst erlangen können, wenn ihre Komplexität dem eines fötalen Hirns in der 20 . Woche p.c. ähnelt und sie zudem die Fähigkeit zur Aufnahme sensorischen Inputs erlangen ${ }^{35}$.

\section{cc) Leidensfähigkeit}

Eine allgemeine Leidensfähigkeit kann über das Empfinden von physischem Schmerz hinausgehen und sich beispielsweise auf psychischen Schmerz erstrecken. Bei Hirnorganoiden könnten solche Leiden z.B. durch sensorische Deprivation aufgrund fehlenden sensorischen Inputs und der daraus resultierenden Abgeschnittenheit von äußeren Reizen und Einflüssen auftreten ${ }^{36}$

Die geringe Komplexität der heutigen Hirnorganoide schließt ein Auftreten solcher Gefühle derzeit jedoch noch aus. Allerdings indizieren Tests, dass Organoide neuronale Netzwerke ausbilden, die zumindest selbst-organisierte Aktivitätsmuster und eine grundlegende Lernfähigkeit unterstützen können ${ }^{37}$.

\section{b) Phänomenales Bewusstsein}

Das phänomenale Bewusstsein wird in der Literatur als das Kernkonzept des Bewusstseins angesehen und häufig mit

22) Lavazza/Massimini, JME 2018, 606

23) Lavazza/Massimini, JME 2018, 606, 607; Tononi/Boly/Massimini u. a., NRN 2016, 450.

24) Shepherd, JME 2018, 611.

25) Casali/Gosseries/Rosanova u.a., Sci Transl Med 2013, 198ra105; Lavazza/Massimini, JME 2018, 606, $608 \mathrm{f}$

26) Sawai/Sakaguchi/Thomas u. a., Stem Cell Reports 2019, 440, 443; Lavazza/Massimini, JME 2018, 606, 608.

27) Koplin/Savulescu, JLME 2019, 760, $761 \mathrm{f}$.

28) Sawai/Sakaguchi/Thomas u.a., Stem Cell Reports 2019, 440 , $442 \mathrm{f}$.

29) Levy, J Conscious Stud 2014, 127, 135; Tooley, in: Kuhse, A Companion to Bioethics, 2009, S. 135.

30) Tooley, in: Kuhse, A Companion to Bioethics, 2009, S. 135.

31) Reardon, Nature 586 (2020), 658.

32) Sawai/Sakaguchi/Thomas u.a., Stem Cell Reports 2019, 440, 442; Farahany/Greely/Hyman u. a., Nature 2018, 429, 430 f.

33) Koplin/Savulescu, JLME 2019, 760, 761.

34) Koplin/Savulescu, JLME 2019, 760, 762.

35) Koplin/Savulescu, JLME 2019, 760, 762; Shepherd, JME 2018, 611.

36) Koplin/Savulescu, JLME 2019, 760, 762; Koch, The feeling of life itself, 2019, $126 \mathrm{ff}$; parallel im Tierschutz: Hirt/Maisack/Moritz, Tierschutzgesetz, 3. Aufl. 2016, \$1, Rdnrn. $19 \mathrm{ff}$., insb. $23 \mathrm{f}$; Lorz/Metzger, Tierschutzgesetz, 7. Aufl. 2016, \$1, Rdnrn. 32 ff., insb. 34; als Indiz herangezogen werden kann auch, dass eine Vernachlässigung und Isolation eines Kindes von der Rechtsprechung als Kindeswohlverletzung anerkannt sind, weil sie geeignet sind die seelische Entwicklung des Kindes zu beeinträchtigen, vgl. Brosius-Gersdorf, in: Dreier, GG, 3. Aufl. 2013, Art. 6, Rdnr. 184; Dettenborn, Kindeswohl und Kindeswille, 2017, S. 46, 49.

37) Lavazza/Massimini, JME 2018, 606, 608; Koplin/Savulescu, JLME 2019, 760, 761; Zafeiriou/Bao/Hudson u.a., Nat Commun 2020, 435 
dem Zugangsbewusstsein verbunden ${ }^{38}$. Gleichwohl wird es als praktisch unmöglich angesehen, das phänomenale Bewusstsein $\mathrm{zu}$ definieren ${ }^{39}$. Es wird als die Art von Bewusstsein verstanden, die beschreibt, dass etwas immer so ist wie bzw. sich etwas immer so anfühlt wie es ist, etwas $\mathrm{zu}$ tun oder zu erfahren (,,what it is like"-ness) ${ }^{40}$. Konkretisierend wird in der Literatur oft das Beispiel angeführt, dass Menschen ohne phänomenales Bewusstsein Zombies wären, Dinge also wahrnehmen könnten, aber diese Wahrnehmungen nicht mit einem Gefühl verbänden ${ }^{41}$.

Abzugrenzen davon ist das Merkmal des Personseins ${ }^{42}$, welches kognitive Kapazitäten wie Autonomie, Rationalität, Emotionalität, moralische Entscheidungsfreiheit oder hoch entwickeltes Selbst-Bewusstsein erfordert ${ }^{43}$. Anders als für einfaches Bewusstsein wird für das Personsein, neben den oben genannten Kriterien, eine Interaktion mit der Umwelt vorausgesetzt, die auch ein Leben in und eine Teilnahme an der Gesellschaft umfasst ${ }^{44}$. Schon weil Hirnorganoiden die Fähigkeit fehlt, sich zu einem vollständigen Menschen zu entwickeln, könnten sie die Voraussetzungen des Personseins nur erfüllen, wenn sie, ggf. durch Verbindung unterschiedlicher Organoide oder durch die Generierung von Mensch-Tier-Chimären, die Fähigkeit zur Verarbeitung von In- und Output von Informationen erwerben. Das unter geringeren Voraussetzungen stehende phänomenale Bewusstsein könnte dagegen schon früher auftreten, sobald eine Wahrnehmung möglich wird.

\section{c) Zugangsbewusstsein}

Zugangsbewusstsein ist die Fähigkeit, Zugang zu Informationen zu haben, also auf den Inhalt von Informationen zugreifen zu können ${ }^{45}$. Ein äußerer Zustand ist zugangsbewusst, wenn über seine Inhalte berichtet werden kann; ist der Zustand nicht zugangsbewusst, können seine Inhalte nicht wiedergegeben werden ${ }^{46}$. Daher wird das Zugangsbewusstsein auch als Informationsverarbeitungskonzept beschrieben ${ }^{47}$. Hinsichtlich seines Auftretens bei Hirnorganoiden gelten die gleichen Voraussetzungen wie für ein Auftreten von phänomenalem Bewusstsein.

\section{d) Selbst-Bewusstsein}

Ein Selbst-Bewusstsein umfasst die Vorstellung, dass es ein „Selbst“ gibt und man diese Vorstellung nutzen kann, sobald man über sich selbst nachdenkt ${ }^{48}$.

Aus dem Vorhandensein von Selbst-Bewusstsein kann zum Beispiel das Interesse folgen, ein Vergnügen zu verfolgen, Schmerz zu vermeiden, eine Begierde zu erfüllen und dem Schönen im Leben nachzukommen ${ }^{49}$. Eine solche Fähigkeit wird bisher nur Menschen und einigen Primaten zugeschrieben $^{50}$. Dass Hirnorganoide diese Bewusstseinsebene erreichen können, dürfte bislang ausgeschlossen sein.

\section{Spiegelung der ethischen Fragen im geltenden Recht}

\section{Vorüberlegungen für ein „Hirnorganoidgesetz“}

Sollten sich in der weiteren Entwicklung von Hirnorganoiden die oben beschriebenen Punkte realisieren, könnte ein weitergehender Schutz derselben notwendig werden. Ein möglicher Weg, diesen Schutz zu verwirklichen, könnte die Schaffung eines Gesetzes sein ${ }^{51}$. Trifft ein solches Gesetz Regelungen über die Forschung an Hirnorganoiden, müsste es mit der Forschungsfreiheit des Art. 5 Abs. 3 S. 1 GG vereinbar sein, um verfassungsgemäß zu sein. Dafür bedürfte es eines Schutzgutes mit Verfassungsrang, das der Gesetzgeber durch die getroffenen Regelungen zu schützen sucht und das gegen die Forschungsfreiheit abzuwägen wäre. Das Vorliegen eines solchen Schutzgutes scheint in Bezug auf Hirnorganoide auf dem derzeitigen naturwissenschaftlichen Entwicklungstand fernliegend. Es wäre aber jedenfalls bei
Hirnorganoiden in weiter fortgeschrittenen Entwicklungsstadien denkbar, wenn sich tatsächlich Aspekte wie etwa das oben beschriebene Bewusstsein realisieren, zum Beispiel durch Ausbildung einer Lern- oder Empfindungsfähigkeit ${ }^{52}$.

Die kontroversen ethischen Fragen, die sich hinsichtlich Hirnorganoiden stellen, sind in ähnlicher Form auch schon in früheren Debatten gestellt worden und haben Eingang in die auf den jeweiligen Gebieten geltenden Gesetze gefunden. Exemplarisch soll auf die Diskussionen zum Schutz menschlicher Entitäten, den Tierschutz und Regelungen für den Umgang mit menschlichem Gewebe eingegangen werden. Im Folgenden werden hierzu Schutzbereich und Zweck der für diese Gebiete geltenden Gesetze erläutert. Darüber hinaus wird mangels einer direkten Anwendbarkeit dieser Gesetze die Übertragbarkeit der dortigen normativen Wertungen oder Regelungskonzepte auf eine mögliche gesetzliche Regelung des Umgangs mit Hirnorganoiden in einem fortgeschrittenen Entwicklungsstadium überprüft ${ }^{53}$.

38) Sawai/Sakaguchi/Thomas u. a., Stem Cell Reports 2019, 440, 443.

39) Sawai/Sakaguchi/Thomas u. a., Stem Cell Reports 2019, 440, 443; Levy, J Conscious Stud 2014, 127, 128; Kahane/Savulescu, JMP 2009, 6, 10.

40) Levy, J Conscious Stud 2014, 127, 128; Kahane/Savulescu, JMP 2009, 6, 10.

41) Levy, J Conscious Stud 2014, 127, 130; Kahane/Savulescu, JMP 2009, 6, 16.

42) Englisch: Personhood.

43) Koplin/Savulescu, JLME 2019, 760, 762; Tooley, in: Kuhse, A Companion to Bioethics, 2009, S. 129, 133.

44) Einen Überblick über die Kriterien (und ihre Anwendung auf Schimpansen) bietet Andrews, Chimpanzee Rights: A Philosophers' Brief, 2018, diese sogar unter Hinweis auf Teilnahme am Gesellschaftsvertrag nach Hobbes.

45) Sawai/Sakaguchi/Thomas u.a., Stem Cell Reports 2019, 440, 443; Levy, J Conscious Stud 2014, 127, 128.

46) Levy, J Conscious Stud. 2014, 127, 128; Block, Behavioral and Brain Sciences 1995, 227, $231 \mathrm{ff}$.

47) Levy, J Conscious Stud. 2014, 127, 129.

48) Sawai/Sakaguchi/Thomas u. a., Stem Cell Reports 2019, 440, 443 Shepherd, EJOP 2017, 398, 399.

49) Sawai/Sakaguchi/Thomas u. a., Stem Cell Reports 2019, 440, 443; Kahane/Savulescu, JMP 2009, 6, 13.

50) Sawai/Sakaguchi/Thomas u. a., Stem Cell Reports 2019, 440, 443 zum Nachweis angewendet wird häufig der sog. Spiegeltest (auch MSR: Mirror Self Recognition Test), den die meisten Primaten, einige Vogel- und Delfinarten und manche Fische bestehen, Gallop, Science 1970, 86; Kinder bestehen den Test ab einem Alter von ca. 20 Monaten, Amsterdam, Dev Psychobiology 1972, 297.

51) Ein solches wird zum Teil auch schon von Forschern gefordert, vgl. Reardon, Nature 2020, 658, 659: „,Researchers are now calling for a set of guidelines, similar to those used in animal research, to guide the humane use of brain organoids and other experiments that could achieve consciousness".

52) Die Frage, ob ein solches Schutzgut von Verfassungsrang vorliegt und welches dieses ggf. sein könnte und in Verbindung damit auch die Frage nach einem eventuellen verfassungsrechtichen Status ist bisher ungelöst. Die Klärung dieser Frage ist Gegenstand einer wissenschaftlichen Arbeit im Rahmen des Projekts „ForInter“ an der Universität Passau.

53) Zusätzlich zur Frage nach einem möglichen Schutzgut von Verfassungsrang stellen sich weitere Rechtsfragen. Hinsichtlich Hirnorganoiden wird zu beantworten sein, ob und wie in eine Erstellung von Hirnorganoiden aus menschlichen Zellen und in eine Forschung an diesen von den Spender:innen eingewilligt werden kann und muss. Hinsichtlich der in den Hirnorganoiden enthaltenen und aus diesen ablesbaren Daten sind Datenschutzfragen zu klären. Neue Fragen stellen sich außerdem im Bereich der Schaffung von und des Umgangs mit Mensch-Tier-Chimären und im Bereich der Abgrenzung von Therapie und Enhancement. Nicht zuletzt könnte das im deutschen Recht bedeutsame Konzept des Hirntods (z.B. in $\$ 3$ Abs. 1 S. 1 Nr. 2 TPG für die Möglichkeit der Organspende) neu zu bewerten sein, wenn Hirnorganoide die Möglichkeit des Ersatzes von beschädigtem Hirngewebe bieten. Auch diese Fragen werden im Rahmen des Forschungsprojekts „ForInter“ behandelt. 


\section{Regelungen zum Schutz menschlicher Entitäten}

a) Embryonenschutzgesetz $z^{54}$

Das ESchG kann auf Hirnorganoide keine direkte Anwendung finden. $\int 8$ Abs. 1 ESchG, der den Begriff des Embryo i. S. d. ESchG und in der Folge dessen Anwendungsbereich definiert, stellt für einen Schutz maßgeblich auf die Entwicklungsfähigkeit der in Frage stehenden (menschlichen) Entität $a b^{55}$. Es schützt ,entwicklungsfähige menschliche Eizelle[n]“ und ,totipotente Zelle[n]“, also ausschließlich Entitäten, die sich zu (geborenen) Menschen entwickeln können ${ }^{56}$. Selbst in seiner weitesten Auslegung, die einen Schutz jeder totipotenten ${ }^{57}$ Zelle vorsieht, ist der Schutz von Hirnorganoiden schon wegen des Fehlens einer solchen Entwicklungsfähigkeit zu einem vollständigen (lebensfähigen) Menschen ausgeschlossen ${ }^{58}$.

Zur Herleitung der normativen Vergleichbarkeit oder Gleichstellung des Embryos mit dem später daraus entstehenden Menschen ${ }^{59}$ (also dem Ergebnis der vorhandenen Entwicklungsfähigkeit) und damit zur Begründung eines Würde- und Lebensschutzes des Embryos wird häufig auf die sog. ,SKIP-“Argumentationsreihe zurückgegriffen. Sie leitet die Schutzwürdigkeit des Embryos aus Spezieszugehörigkeit zur Spezies Mensch (S), Kontinuität der Entwicklung vom Embryo zum Menschen derart, dass die Ziehung von Schutzwürdigkeitsschwellen willkürlich wäre $(\mathrm{K})$, Identität des geborenen Menschen mit dem Embryo, aus dem er hervorgegangen ist (I), und der Tatsache ab, dass Embryonen sich zu geborenen Menschen, mit dann vollem moralischen Status, entwickeln können und damit zwar nicht aktuell, aber potentiell über die würdebegründenden Eigenschaften verfügen $(\mathrm{P})^{60}$. Wendet man diese Kriterien (quasi zur Prüfung einer Anwendbarkeit der gleichen Schutzstandards) auf Hirnorganoide an, stellt man fest, dass sich die Spezieszugehörigkeit wohl noch bejahen lässt. Die Erfüllung der übrigen Kriterien durch Hirnorganoide ist allerdings ausgeschlossen. Auch das Vorliegen eines noch so weit entwickelten Bewusstseins in einem Hirnorganoid würde an der fehlenden Entwicklungsfähigkeit hin zum geborenen Menschen nichts ändern.

Eine über den Wortlaut des ESchG hinausgehende Anwendung auf Hirnorganoide ist darüber hinaus schon wegen des nebenstrafrechtlichen Charakters des ESchG und des Analogieverbots aus Art. 103 Abs. 2 GG ausgeschlossen ${ }^{61}$.

Nützlich dürfte aber der Rechtsgedanke sein, dass Entitäten, die humanspezifische Fähigkeiten ähnlich einem geborenen Menschen haben (könnten), grundsätzlich ein (unter Umständen strafbewehrter) Schutz zukommen kann, namentlich dann, wenn sie für Zwecke der Forschung geschaffen oder verwendet werden (sollen).

\section{b) Grundgesetz und Strafgesetzbuch ${ }^{62}$}

Das StGB enthält in $\$ \$ 218$ ff. StGB Vorschriften über die Strafbarkeit des Schwangerschaftsabbruchs. Eine direkte Anwendung auf Hirnorganoide können diese Vorschriften des StGB nicht finden. Die Idee eines von der Entwicklungsstufe und insoweit von der Leidens- und Schmerzfähigkeit abhängenden, gestuften (Lebens-) Schutzes, wie er in einer früheren Fassung des $\$ 218$ a StGB, der sog. ,,Fristenlösung“ von $1974^{63}$, enthalten war, ist allerdings ein Grundgedanke, der sich auch in der heute geltenden Fassung der \$S $218 \mathrm{ff}$. StGB wiederfinden und für eine mögliche gesetzliche Regelung von Hirnorganoiden nutzbar machen lässt, ohne dass es dabei, eben weil es sich bei Hirnorganoiden nach dem derzeitigen Forschungsstand nicht um Menschen handelt, in der Intensität der Schwangerschaftsabbruchsurteile des BVerfG auf die den Lebensschutz betreffenden Gedanken ankommt.

Das BVerfG betrachtet Embryonen zumindest ab Nidation als Träger der Menschenwürde gem. Art. 1 Abs. 1 S. 1 $\mathrm{GG}^{64}$ und hat dafür die Formel „Wo menschliches Leben existiert, kommt ihm Menschenwürde $\mathrm{zu}^{\text {“65 }}$ geprägt. Im Hinblick auf Embryonen ist dieses menschliche Leben zu jedem Zeitpunkt gleichermaßen absolut schutzwürdig ${ }^{66}$ Gleichzeitig bestätigt das BVerfG die grundsätzliche Möglichkeit eines unterschiedlichen Schutzes von geborenem und ungeborenem Leben ${ }^{67}$. Darüber hinaus nimmt eine verbreitete Ansicht in der Literatur, entgegen dem BVerfG, an, dass eine Abstufung des Würde- und Lebensschutzes (Art. 1 Abs. 1, Art. 2 Abs. 2 S. 1 GG) anhand des Entwicklungsstadiums bzw. der Entwicklungsphasen eines Embryos während des Verlaufs der Schwangerschaft möglich ist ${ }^{68}$ und sich die sogleich gezeigten relevanten Ent-

54) Gesetz zum Schutz von Embryonen (Embryonenschutzgesetz ESchG) v. 13.12.1990 (BGBl. I S. 2746), zuletzt geändert durch Art. 1 d. G v. 21.11.2011 (BGB1. I S. 2228).

55) BT-Dr. 11/5460, S. 12; 13/11263, S. 14. Dabei ist Entwicklungsfähigkeit in den frühen Stadien gleichbedeutend mit einer Teilungsfähigkeit. Vgl. auch Günther/Taupitz/Kaiser, Embryonenschutzgesetz, 2. Aufl. 2014, C.II. \$8, Rdnrn. 3, 7, 9 ff.

56) Müller-Terpitz, in: Spickhoff, Medizinrecht, 3. Aufl. 2018, \8 ESchG, Rdnrn. 2 f.

57) Zum Begriff der Totipotenz in $₫ 8$ Abs. 1 ESchG umfassend Laimböck, Totipotenz, 2014, S. $175 \mathrm{ff}$.

58) Vgl. Günther/Taupitz/Kaiser, Embryonenschutzgesetz, 2. Aufl. 2014, C.II. \$8, Rdnr. 8; Mutmaßungen über das Verbinden aller relevanten Organoide zu einem vollständigen Organismus erscheinen sehr weit hergeholt und würden an dieser Stelle zu weit führen. Organoidsysteme, die mehrere Organoide miteinander verbinden, bekannt unter den Begriffen „Organ-on-a-chip“ oder „Human-on-a-chip“, erscheinen dagegen nicht unrealistisch, vgl. GSCN, White Paper ,Organoide - von der Stammzelle zur zukunftsweisenden Technologie“. Zur Anwendbarkeit des ESchG auf Organoide auch Taupitz, MedR 2021, 409.

59) Die Frage, ob Hirnorganoide in ihrem normativen Status ggf. menschlichen Embryonen anzupassen sind, wird auch im White Paper ,Organoide - Von der Stammzelle zur zukunftsweisenden Technologie" der IA Gentechnologiebericht der BBAW und des GSCN (dort S. 40) aufgeworfen.

60) Vgl. Ach/Schöne-Seifert/Siep, JFWE 2015, 261, 272, 294.

61) Enghofer, Humane artifizielle Gameten, 2019, 285 ff. für artifizielle Gameten; Günther/Taupitz/Kaiser, Embryonenschutzgesetz, 2. Aufl. 2014, C.II. \8, Rdnr. 8 mit Hinweis auf ,neue Entitäten" in Rdnrn. $48 \mathrm{ff}$.

62) Strafgesetzbuch (StGB) i.d.F. d. Bekanntmachung v. 13.11.1998 (BGBl. I S. 3322), zuletzt geändert durch Art. 1 d. G. v. 9.10.2020 (BGBl. I S. 2075).

63) 218 a StGB i.d.F.d. 5. StrRG v. 18.6.1974 (BGBl. I, $1297 \mathrm{ff}$ ), vgl. auch u. Fn. 73. Die echte Fristenregelung des 5. StrRG und die Für-Nicht-Rechtswidrig-Erklärung des \218a StGB i.d. F.d. SFHG v. 27. 7. 1992 (BGBl. I S. 1398 ff.) hatte das BVerfG in den Entscheidungen BVerfGE 39, 1 und BVerfGE 88, 203 für verfassungswidrig erklärt. Die heute geltende Regelung knüpft zwar immer noch an die dort etablierten zeitlichen Grenzen an, trifft aber keine Aussage über die Rechtmäßigkeit des Schwangerschaftsabbruchs.

64) BVerfGE 88, 203, 251 f.; Dederer, AöR 2002, 1, 7.

65) BVerfGE 39, 1, 41; 88, 203, 252; Herdegen, in: Maunz/Dürig/Herzog, GG (2009), Art. 1 Abs. 1, Rdnr. 61.

66) BVerfGE 39, 1, 43: „,Dieser Vorrang [des Lebensschutzes des nasciturus] gilt grundsätzlich für die gesamte Dauer der Schwangerschaft und darf auch nicht für eine bestimmte Frist in Frage gestellt werden“; 88, 203, 255, wonach ,,der Schwangerschaftsabbruch für die ganze Dauer der Schwangerschaft grundsätzlich als Unrecht angesehen" werden muss.

67) BVerfGE 39, 1, 45 „Der Gesetzgeber ist grundsätzlich nicht verpflichtet, die gleichen Maßnahmen strafrechtlicher Art zum Schutze des ungeborenen Lebens zu ergreifen, wie er sie zur Sicherung des geborenen Lebens für zweckdienlich und geboten hält.“ Zur Inkonsequenz dieser Ansicht vgl. Dreier, ZRP 2002, 377, 378 f., Dederer, Jahrbuch für Ethik und Recht 2020, 53, 61.

68) Gropp, in: Kreuzer/Backes, Fühlende und denkende Kriminalwissenschaften, 1999, S. 285, $290 \mathrm{ff.}$., Gropp, in: Schumann, Verantwortungsbewusste Konfliktlösungen bei embryopathischem Befund, 2008, S. 19, 22 ff. (dort: ,gestuft und gradualisiert"); Dreier, ZRP 2002, 377, 379 ff.; kritisch Jakobs, JR 2000, $404 \mathrm{ff}$. 
wicklungszeitpunkte auch in den Regelungen der $\$ \$ 218 \mathrm{ff}$. StGB widerspiegeln ${ }^{69}$.

Erster relevanter Zeitpunkt ist der Zeitpunkt der Nidation, also der Einnistung des befruchteten Eies in die Gebärmutterschleimhaut. Darauf folgen der Beginn der Entwicklung des menschlichen Gehirns und des Rückenmarks in der dritten Woche p.c., die Entwicklung der freien Nervenendigungen um die siebte Woche p.c. (ermöglicht objektive Schmerzempfindung durch Aktivierung derselben) und die Entwicklung erster auf Rückenmarksebene verschalteter Schutzreflexe bis zur 14. Woche p.c., welche jedoch noch nicht an das höhere zentrale Nervensystem angeschlossen sind. Zwischen der 18. und der 23. Woche p.c. zeigen sich erste Stressreaktionen, die darauf hindeuten, dass die Stressinformationen den für ihre Verarbeitung zuständigen Thalamus erreichen (subjektive Schmerzwahrnehmung) ${ }^{70}$.

$\$ 218$ Abs. 1 S. 1 StGB stellt den Schwangerschaftsabbruch grundsätzlich unter Strafe, bietet aber dennoch in gewissen Abschnitten der Schwangerschaft die Möglichkeit, einen solchen Eingriff erlaubt oder zumindest straflos vorzunehmen. Dabei gelten Handlungen, die schon vor dem Zeitpunkt der Nidation eingreifen, gem. $\$ 218$ Abs. 1 S. 2 StGB schon nicht als Schwangerschaftsabbruch. Weiterhin wird ein Schwangerschaftsabbruch gem. \$218a Abs. 1 StGB in den ersten 12 Wochen p.c. unter bestimmten Voraussetzungen vom Tatbestand ausgenommen. Eine Abtreibung des Fötus nach Überschreitung der 12. Woche p.c. bleibt für die Schwangere bis zur 22. Woche p.c. straffrei, wenn sie eine Beratung gem. \219 StGB wahrgenommen hat ( $\$ 218$ Abs. 4 StGB). Danach ist ein Abbruch nur noch aufgrund einer medizinisch-sozialen und der seit 1995 in diese integrierten embryopathischen Indikation ${ }^{71}$, dann aber theoretisch bis zum letzten Tag der Schwangerschaft, erlaubt.

Diese Anknüpfung an fest definierte Zeitpunkte soll, neben einer Verwirklichung eines bestmöglichen Lebensschutzes für das $\mathrm{Kind}^{72}$, nicht nur das Eingriffsrisiko für Schwangere verringern, sondern auch dem ungeborenen Kind unnötiges Leid ersparen ${ }^{73}$.

Während anfangs die rechtliche Schwelle für einen Eingriff in den Lebensschutz des Fötus also, jedenfalls faktisch, noch vergleichsweise gering ist, steigt diese mit fortschreitender Entwicklung des Fötus (und seiner Bewusstseins-, Schmerz- und Stresswahrnehmungskapazitäten) an.

\section{c) Stammzellgesetz ${ }^{74}$}

Anders als das nebenstrafrechtliche ESchG trifft das StZG Regelungen nach der Art eines Verwaltungsgesetzes. Es ist als Verbotsgesetz mit strafbewehrtem Genehmigungsvorbehalt formuliert ${ }^{75}$.

Auch das StZG findet auf Hirnorganoide keine Anwendung: Ausweislich seines $\$ 2$ gilt das Stammzellgesetz, ,für die Einfuhr [und Verwendung] von embryonalen Stammzellen“. Grundsätzlich besteht zwar die Möglichkeit, Hirnorganoide auch aus embryonalen Stammzellen (eSZ) herzustellen, in der Praxis werden dafür jedoch ausschließlich iPSZ verwendet. Mithin bleibt das StZG, das ohnehin wegen seines engen Anwendungsbereichs nur auf die Forschung an den hergestellten Hirnorganoiden ${ }^{76}$, nicht aber auf eine mögliche therapeutische Verwendung derselben Anwendung finden könnte $\left(\$ 4\right.$ Abs. 1, 2), unangewendet ${ }^{77}$.

Allerdings enthält das StZG in $₫ 6$ Vorschriften über die Notwendigkeit einer Genehmigung der Einfuhr und Verwendung von eSZ. In $\$ 8$ normiert es die Einrichtung einer zentralen Ethikkommission für Stammzellforschung und schreibt in $\$ 11$ die Einrichtung eines Registers über die genehmigten Forschungsvorhaben vor.

Je nach Entwicklungsstatus der in Frage stehenden Hirnorganoide könnten auch für diese Genehmigungs- und Registervorschriften eingefügt werden. Ebenso könnte die Einrichtung einer Ethikkommission, welche z.B. in das Genehmigungsverfahren eingebunden ist, erforderlich sein. Auch die Abfassung eines möglichen Gesetzes als Verbotsgesetz mit Genehmigungsvorbehalt könnte eine Option sein, wenn man nicht, wie im ESchG, eine Regelung durch echtes Nebenstrafrecht wegen der Wichtigkeit der festgestellten Schutzgüter für angezeigt hält.

\section{Tierschutzrecht}

Die Ausgestaltung des Tierschutzes erfolgt in Deutschland als ethischer Tierschutz ${ }^{78}$. Er ist Kern aller tierschutzrechtlichen Regelwerke und überdies seit dem 1.8.2002 als Staatszielbestimmung in Art. 20a GG verankert ${ }^{79}$. Gem. \1 S. 1 TierSchG ${ }^{80}$ dient das Gesetz dem Schutz des Lebens und Wohlbefindens des Tieres als Mitgeschöpf.

Eine Anwendung der Regelungen des Tierschutzgesetzes auf Hirnorganoide, auch nur in analoger Form, scheidet ebenfalls von vornherein aus. Sie wäre zwar auf den ersten Blick grundsätzlich denkbar (immerhin geht es in beiden Fällen, Tierschutz und Schutz von Hirnorganoiden, um den besonderen Schutz von Entitäten, die in irgendeiner Form Bewusstsein aufweisen (können werden)), allerdings erfordern Analogien grundsätzlich eine planwidrige Regelungslücke und eine vergleichbare Interessenlage ${ }^{81}$. Während sich letztere ggf. noch denken ließe (s. o.), fehlt es jedenfalls an einer Regelungslücke ${ }^{82}$. Dies betrifft freilich

69) Dreier, ZRP 2002, 377, 378; Herdegen, in: Maunz/Dürig/Herzog, GG (2009), Art. 1 Abs. 1, Rdnr. 60.

70) Zum Ganzen: Dolderer, Menschenwürde und Spätabbruch, 2012, S. $12 \mathrm{f}$.

71) Gropp, in: Schumann, Verantwortungsbewusste Konfliktlösungen bei embryopathischem Befund, 2008, S. 19, $26 \mathrm{f}$

72) BVerfGE 88, 203, 280 („Verbündete“), insbesondere in einem Zeitraum der Schwangerschaft, in dem die Schwangerschaft von außen noch nicht erkennbar ist.

73) Gropp, in: MüKo/StGB, 3. Aufl. 2017, \218a StGB, Rdnr. 17 („Leiden [...], die mit der Tötung in einem späteren Stadium verbunden sind"); Kröger, in: LK-StGB, 12. Aufl. 2019, Vor $0 \$ 218 \mathrm{ff}$., Rdnr. 1; Eser/Weißer, in: Schönke/Schröder StGB, 30. Aufl. 2019, Vor $\$ \$ 218$ bis $219 b$, Rdnr. 9; $\$ 218$ a, Rdnr. 11, unter Hinweis auf BT-Dr. 6/3434, S. 26 (dort ,ethische Indikation“); 7/375, S. 7 (,In den ersten drei Monaten darf eine relativ geringe Gefährlichkeit unterstellt werden“).

74) Gesetz zur Sicherstellung des Embryonenschutzes im Zusammenhang mit Einfuhr und Verwendung menschlicher embryonaler Stammzellen (Stammzellgesetz - StZG) v. 28.6.2002 (BGBl. I S. 2277), zuletzt geändert durch Art. 50 d.G.v. 29.3.2017 (BGB1. I S. 626).

75) Müller-Terpitz in: Spickhoff, Medizinrecht, 3. Aufl. 2018, Vorbemerkung, Rdnr. 2; Häberle in: Erbs/Kohlhaas, Strafrechtliche Nebengesetze, 09/2015, \4, Rdnrn. 1f.; Dederer, StZG, 1. Aufl. 2012, Einleitung, Rdnr. 5.

76) Für eine Anwendbarkeit auch auf ,,(gentechnische) Veränderung, Ausdifferenzierung" und den Verbrauch von eSZ, in der Folge konsequenterweise wohl auch auf die Herstellung von Hirnorganoiden aus eSZ: Dederer, StZG, 1. Aufl. 2012, \$2, Rdnr. 2; MüllerTerpitz in: Spickhoff, Medizinrecht, 3. Aufl. 2018, \2, Rdnr. 3.

77) Dederer, StZG, 1. Aufl. 2012, \$4, Rdnr. 3.

78) Prinzip des ,ethischen Tierschutzes“: BVerfGE 101, 1, 5; Erwgrd. 23 zur Tierversuchs-RL; BT-Dr. 14/8860, S. 3 (zu Art. 20a GG), Hirt/Maisack/Moritz, Tierschutzgesetz, 3. Aufl. 2016, Einf., Rdnr. 5; §1, Rdnrn. 2 ff.; Lorz/Metzger, Tierschutzgesetz, 7. Aufl. 2016, Einf., Rdnr. 21; $\$ 1$, Rdnr. 1.

79) BT-Dr. 14/8860, S. 3; zur geschichtlichen Entwicklung des ethischen Ansatzpunktes im Tierschutz Hirt/Maisack/Moritz, Tierschutzgesetz, 3. Aufl. 2016, Einf., Rdnrn. 1 ff., zum ethischen Tierschutz, Rdnr. 24; Scholz, in: Maunz/Dürig/Herzog, GG (2002), Art. 20a, Rdnr. 59.

80) Tierschutzgesetz i.d.F.d. Bekanntmachung v. 18.5.2006 (BGB1. I S. 1206, 1313), zuletzt geändert durch Art. 280 d. VO v. 19.6.2020 (BGBl. I S. 1328).

81) Vgl. z.B. BGH, NJW 2003, 1932

82) Aus humanen iPSZ gezüchtete Hirnorganoide könnten in eine solche Regelungslücke auch nicht eindringen. 
nur den Teil der Forschung an Hirnorganoiden selbst, nicht jedoch die mögliche Erforschung von Hirnorganoiden im Tierversuch, auf die das Tierschutzgesetz mit seinen Regelungen für Tierversuche in $\$ \$ 7$ bis 9 TierSchG ohnehin Anwendung findet ${ }^{83}$.

Auch im Tierschutzrecht findet sich jedoch eine Reihe übertragbarer Rechtsgedanken und konkret übertragbarer Maßnahmen. Zunächst bietet das Tierschutzrecht in seinen Bestimmungen über Tierversuche unterschiedliche Schutzstufen für unterschiedliche Arten von Tieren. Dabei genießen Primaten, Katzen und Hunde ${ }^{84}$ einen höheren Schutz als sonstige Wirbeltiere und diese wiederum einen höheren Schutz als Wirbellose mit der Ausnahme von Kopffüßern und Zehnfußkrebsen. Ausdruck dessen ist unter anderem das Erfordernis einer behördlichen $\mathrm{Ge}$ nehmigung für Versuche mit Wirbeltieren ${ }^{85}$, wohingegen für Versuche an höherentwickelten Weichtieren wie Tintenfischen lediglich eine Anzeige vorgeschrieben wird ${ }^{86}$. Tiere höherer Entwicklungsstufen wird dabei eine erhöhte Schmerzempfindungsfähigkeit und Leidensfähigkeit zuerkannt ${ }^{87}$. Ein solcher stufenweiser (gradueller) Schut ${ }^{88}$ ließe sich auch auf sich entwickelnde Hirnorganoide mit zunehmend ausgeprägtem Bewusstsein übertragen $^{89}$.

In $\$ 1$ S. 2 des TierSchG heißt es ,Niemand darf einem Tier ohne vernünftigen Grund Schmerzen, Leiden oder Schäden zufügen“. In $\$ 7$ a Abs. 1 TierSchG werden die „,vernünftigen Gründe“, u.a. die Grundlagenforschung (Nr. 1), die Vorbeugung, Erkennung oder Behandlung von Krankheiten (Nr. 2) und die Entwicklung und Herstellung sowie Prüfung der Wirksamkeit und Unbedenklichkeit von Arzneimitteln (Nr. 4), zu denen Tierversuche durchgeführt werden dürfen, abschließend aufgezählt. Diese Regelungen sind auch eine Ausgestaltung der sog. „Three R's" - Reduce, Refine und Replace, die $2013^{90} \mathrm{im}$ Wege der Umsetzung der EU-Tierversuchsrichtline 2010/63/EU ${ }^{91}$ in das deutsche TierSchG aufgenommen wurden $^{92}$. Erstmals 1959 von Russell/Burch in Bezug auf die Beseitigung der Unmenschlichkeit bei Tierversuchen erwähnt, sind sie seitdem zu einem Standard der Tierversuchsregulierung geworden ${ }^{93}$. Reduce zielt auf die Verringerung der Anzahl der Versuchstiere auf ein Minimum ab; Refine auf die Minderung des Leidens der Versuchstiere. Replace steht für die Vermeidung von Tierversuchen, wo auch immer möglich, durch den Einsatz von Alternativmethoden ${ }^{94}$.

Dieses 3R-Prinzip ist von Koplin und Savulescu weitergedacht und in einem Gedankenexperiment auf Hirnorganoide angewendet worden ${ }^{95}$. Nicht unähnlich den Regelungen zum Tierschutz, die die Forschung an Tieren nach einer Güterabwägung zulassen, könnte eine solche Konstruktion auch für Hirnorganoide geschaffen werden.

In Kombination mit den obigen Ausführungen zur Messung von Bewusstsein in Graden würde dies eine strenge Verhältnismäßigkeitsprüfung und Interessenabwägung zwischen Mittel und Zweck erfordern. Eine Forschung wäre dann nur zulässig, wenn (1.) die beabsichtigten Untersuchungen zu dem angestrebten Ziel ohne Forschung an Hirnorganoiden (mit der Fähigkeit zu Bewusstsein) nicht mit gleichem Erfolg durchgeführt werden könnte, (2.) sichergestellt ist, dass die Hirnorganoide, an denen geforscht wird, jeweils nur das Maß an Bewusstsein aufweisen, das für den Erfolg der jeweiligen Forschung unbedingt notwendig ist, und (3.) Vorkehrungen dafür getroffen werden, dass die negativen Auswirkungen und Nachwirkungen auf die Hirnorganoide so gering wie möglich sind ${ }^{96}$.

Auch Vorgaben zur Genehmigungsbedürftigkeit oder Anzeige von Tierversuchen ${ }^{97}$, die Einberufung einer Tierschutzkommission $^{98}$ oder Straf- und Bußgeldvorschriften zur Durchsetzung ${ }^{99}$ könnten entsprechend Eingang in ein Regelungswerk für Hirnorganoide finden.

\section{Regelungen zum Umgang mit menschlichem Gewebe}

Der Umgang mit Geweben und Organen richtet sich in Deutschland grundsätzlich nach dem Transplantationsgesetz $^{100}$. Gem. \$1a Nr. 1 TPG sind „Organe [...] alle aus verschiedenen Geweben bestehenden, differenzierten Teile des menschlichen Körpers, die in Bezug auf Struktur, Blutgefäßversorgung und Fähigkeit zum Vollzug physiologischer Funktionen eine funktionale Einheit bilden, einschließlich der Organteile und einzelnen Gewebe eines Organs“. Gem. \$1 a Nr. 4 sind Gewebe ,,alle aus Zellen bestehenden Bestandteile des menschlichen Körpers, die keine Organe nach Nummer 1 sind“. Hirnorganoide unterfallen dieser Definition $^{101}$. Allerdings gilt das TPG ausweislich seines $\$ 1$ Abs. 2 lediglich ,für die Spende und die Entnahme von menschlichen Organen oder Geweben zum Zwecke der Übertragung sowie für die Übertragung der Organe oder der Gewebe einschließlich der Vorbereitung dieser

83) So auch Taupitz, MedR 2020, 805, 813, jedenfalls für Organoide im Allgemeinen,

84) Vgl. dazu z.B. $\$ \$ 4$ Abs. 3, 8a Abs. 2 Nr. 1, 9 Abs. 3 Nr. 1, 11a Abs. 1, 3, 16 und 18 TierSchG.

85) Vgl. z.B. $\int \$ 4,4 a, 6,8$ TierSchG; Max-Planck-Gesellschaft, Genehmigung von Tierversuchen, https://www.mpg.de/ 10885060/genehmigung, Zugriff am: 21.7.2021.

86) Vgl. z.B. \$8 Abs. 3, 4 TierSchG

87) Vgl. BT-Dr. 6/2559. S. 10: „Wirbeltiere reagieren infolge ihrer differenzierteren Innervierung im Hinblick auf Schmerzregung, Schmerzleitung und Schmerzempfindung im Vergleich zu anderen Tieren wesentlich stärker"; S. 17: „Wirbeltiere sind nach der zoologischen Einteilung höherorganisierte Tiere, die über ein Zentralnervensystem verfügen. Diese Tiere haben somit ein hochdifferenziertes Schmerzleitungssystem und ein ausgeprägtes Schmerzempfindungsvermögen.“; 13/7015, S. 22 Aufnahme von Fischen, da wissenschaftliche Erkenntnisse nahelegen, dass auch diese eine größere Leidensfähigkeit haben als zunächst angenommen. Vgl. auch Lorz/Metzger, Tierschutzgesetz, 7. Aufl. 2016, \$1, Rdnrn. 19 ff., \$7a, Rdnr. 28; Umfassend auch Hirt/Maisack/Moritz, Tierschutzgesetz, 3. Aufl. 2016, $\$ 1$, Rdnrn. $12 \mathrm{ff}$.

88) Zum Auftreten von Bewusstsein in Graden schon oben II. 2 und Tooley, in: Kuhse, A Companion to Bioethics, 2009, S. 129, $134 \mathrm{f}$.

89) Der Schutz von Potentialen bzw. das Konzept unterschiedlicher Schutzstufen für unterschiedlich starke Ausprägungen von $\mathrm{Be}$ wusstsein, Wahrnehmung, Schmerzempfinden und Leidensfähigkeit finden sich zudem auch in der Debatte um den Schutz von Embryonen und zur Zulässigkeit des Schwangerschaftsabbruchs (vgl. schon oben III. 1. b.).

90) Drittes G. zur Änderung d. TierSchG v. 4.7.2013 (BGBl. I S. 2182).

91) RL 2010/63/EU des Europäischen Parlaments und des Rates v. 22.9.2010 zum Schutz der für wissenschaftliche Zwecke verwendeten Tiere.

92) BT-Dr. 17/10572, S. 1, 20, 25; BR-Dr. 300/12, S. 1.

93) Russel/Burch, The Principles of Humane Experimental Technique, 1959, S. 64; vgl. auch Art. 4 EU-Tierversuchs-RL.

94) Bundesinstitut für Risikobewertung, Deutsches Zentrum zum Schutz von Versuchstieren, https://www.bfr.bund.de/de/deutsches_zentrum_zum_schutz_von_versuchstieren.html, Zugriff am 21.7.2021

95) Koplin/Savulescu, JLME 2019, 760, 763.

96) Wir wollen allerdings nicht so weit gehen als Mutmaßungen über die Voraussetzungen einer ,,artgerechten Haltung“ anzustellen.

97) $\$ \$ 8,8$ a TierSchG.

98) \$16b TierSchG

99) Vgl. \$\$ $17 \mathrm{ff}$. TierSchG.

100) Gesetz über die Spende, Entnahme und Übertragung von Organen und Geweben (Transplantationgesetz - TPG) i.d.F.d. Bekanntmachung v. 4.9.2007 (BGBl. S. 2206), zuletzt geändert durch Art. 6 d. G.v. 14. 10.2020 (BGBl. I S. 2115).

101) Zur Geltung für Organoide im Allgemeinen Taupitz, MedR $2020,805,810 \mathrm{f}$. 
Maßnahmen“"102. Sollen die Organoide nicht transplantiert werden, sondern ausschließlich zu Forschungszwecken verwendet werden, findet das Transplantationsgesetz daher weder auf sie noch auf die Entnahme des Zellmaterials zu ihrer Herstellung Anwendung ${ }^{103}$.

Unabhängig davon kann das TPG aber auf eine Transplantation von (fortgeschrittenen, z. B. bewusstseinsfähigen) Hirnorganoiden schon deshalb keine Anwendung finden, weil das TPG nicht darauf ausgelegt ist, Regelungen für einen ggf. notwendigen Schutz der zu transplantierenden Hirnorganoide zu treffen. Zweck des die relevanten Vorschriften des TPG ändernden GewebeG ${ }^{104}$ war es, die „Qualität und Sicherheit von Geweben“ zu gewährleisten und dadurch die „Verhütung der Übertragung von Krankheiten“" zu erreichen. Mit anderen Worten dient das Gesetz dem Gesundheitsschutz der Patient:innen ${ }^{105}$, könnte also nicht Hirnorganoide mit Bewusstsein als solche schützen ${ }^{106}$.

Ähnliche Feststellungen lassen sich auch für weitere in Betracht kommende Regelungswerke aus dem Bereich des Medizinrechts treffen. Das $\mathrm{AMG}^{107}$ - unter das Hirnorganoide als ATMP gem. \$4 Abs. 9 AMG, in den meisten Fällen als biotechnologisch bearbeitete Gewebeprodukte gem. Art. 2 lit. a) dritter Spiegelstrich i. V. mit lit. b) ATMP-VO ${ }^{108}$, fallen und das in $\$ 20 b$ Abs. 1 S. 1 Regelungen für den Umgang mit zu therapeutischen Zwecken entnommenen Geweben enthält - dient ausweislich seiner Gesetzesbegründung der Verwirklichung einer optimalen Arzneimittelsicherheit ${ }^{109}$. Gleichermaßen dient das Gentechnikgesetz ${ }^{110}$ der Förderung der „Forschung und Anwendung der Gentechnik in Deutschland" und hat als oberstes Ziel den "Schutz von Mensch und Umwelt"“111. Alle haben gemeinsam, dass sie die in Bezug auf Hirnorganoide auftretenden ethischen Fragen derzeit nicht beantworten und - jedenfalls wenn sie ihrem ursprünglichen Gesetzeszweck treubleiben sollen - auch nicht werden beantworten können. Die bestehenden Regelungen des Medizinrechts sind für den Umgang mit den hier behandelten speziellen Problemfeldern fortgeschrittener Hirnorganoide, jedenfalls hinsichtlich einer Forschung mit und an diesen, ungeeignet. Sowohl auf eine Forschung an Hirnorganoiden in ihrem derzeitigen Entwicklungsstadium als auch auf eine Therapie mit Hirnorganoiden können sie, ggf. nach Klärung der weiteren Rechtsfragen ${ }^{112}$, keine Anwendung finden.

Übertragbar dürften allerdings die grundsätzlichen Wertungen der Gesetze zum Umgang mit menschlichem Gewebe sein. So bedarf die Entnahme von Gewebe stets einer Einwilligung der Patient:innen/Proband:innen. Bei der Entnahme von Gewebeproben ergeben sich darüber hinaus eigentumsrechtliche Probleme, weil der menschliche Körper als sogenanntes res extra commercium zunächst außerhalb des Eigentumsrechts steht ${ }^{113}$. Nach der Rechtsprechung des BGH richtet sich die Zuordnung des entnommenen Körperteils oder der Körpersubstanz danach, ob das Organ oder die Substanz eine Funktion für den Körper übernimmt ${ }^{114}$. Mit der Entnahme der Proben von Patient:innen werden diese dann nach herrschender Meinung zu eigentumsfähigen Sachen i.S.v. $\$ 90$ BGB ggf. i. V. mit $\$ 92 \mathrm{BGB}^{115}$. Sie sind dann nicht mehr im selben $M a ß$ wie ein Mensch geschützt und können in der Forschung einfacher verwendet werden. Die Schwelle für diese Einstufung als Sache könnte für Hirnorganoide neu zu bestimmen $\operatorname{sein}^{116}$.

\section{Ergebnis}

Keines der hier besprochenen Regelwerke kann in seiner derzeitigen Form auf den Schutz und den Umgang mit Hirnorganoiden in einem späteren Entwicklungsstadium ohne Weiteres angewendet werden. Gleichwohl enthält die
Gesamtheit der vorhandenen Regelwerke alle notwendigen Regelungskonzepte, um eine möglicherweise notwendige, ganzheitliche gesetzliche Regelung für die Behandlung von Hirnorganoiden in Forschung und Therapie zu schaffen, die nicht nur in der Lage wäre, die wesentlichen ethischen Fragen zu beantworten, sondern sich auch in das System des geltenden Medizinrechts einfügen könnte.

Zusammenfassend müsste ein solches Regelwerk jedenfalls die folgenden Punkte umfassen, um einen ausreichenden Schutz von Hirnorganoiden sicherzustellen, in denen

102) Anders als Taupitz, MedR 2020, 805, 811 sehen wir in dieser Formulierung, die auf den ersten Blick eine Identität zwischen entnommenem und transplantiertem Organ oder Gewebe zu suggerieren scheint, keinen Hinderungsgrund dafür, die Transplantation von Organoiden unter das TPG zu fassen. Eine Entnahme ist gem. \1a Nr. 6 TPG die ,Gewinnung von [...] Geweben“, ausweislich der Gesetzesbegründung, BT-Dr. 16/3146, S. 24 gerade nicht nur die ,unmittelbare Gewinnung“, sondern auch die Gewinnung durch „Be- oder Weiterverarbeitung“. Die Definition orientiert sich weiterhin an Art. 3 lit. f. der Richtlinie 2004/23/EG des Europäischen Parlaments und des Rates v. 31.3.2004 (Gewebe-RL), nach der „Beschaffung“ ein Prozess ist, ,,durch den Gewebe oder Zellen verfügbar gemacht werden“. Zudem erfolgt die Verwendung des Begriffes in einem arzneimittelrechtlichen Kontext, der Gewinnung in $\$ 4$ Abs. 14 AMG als eine Form der Herstellung versteht, die in $\$ 20$ b Abs. 1 S. 1 AMG auch definiert wird. Die hier vertretene Auffassung ist auch nur konsequent, wenn man bedenkt, dass auch Taupitz, MedR 2020, 805, 809; 2021, 412 jedenfalls auf die Spende und Entnahme von Geweben für die Herstellung von Organoiden, außer diese geschieht ausschließlich für Forschungszwecke, die Regelungen des TPG anwenden will. Wie auf die Transplantation von Organoiden allgemein kann dann unserer Ansicht nach auch die Transplantation jedenfalls heutiger Hirnorganoide unter das TPG gefasst werden.

103) BT-Dr. 16/3146, S. 23; Erwgrd. 11 der Gewebe-RL; Taupitz, MedR 2020, 805, 809. Erfolgt die Nutzung der Gewebe ausschließlich für Forschungszwecke, findet keine in Deutschland bestehende Regelung direkte Anwendung. Stattdessen greifen die rechtlichen Grundgedanken aller relevanten Gesetze gemeinsam. Zudem finden (rechtlich unverbindliche) Regeln Anwendung, die von internationalen Einrichtungen wie der International Society for Stem Cell Research (ISSCR) herausgegeben werden und die daher, anders als nationale Gesetze, auch international Geltung beanspruchen bzw. von den anwendenden Forscher:innen freiwillig befolgt werden. Für die Forschung an Stammzellen sind dies z.B. die 2016 erschienenen Guidelines for Clinical Trials and Clinical Translation.

104) Gesetz über Qualität und Sicherheit von menschlichen Geweben und Zellen (GewebeG) v. 20.7.2007 (BGBl. I S. 1574) zuletzt geändert durch G. v. 9.8.2019 (BGB1. I S. 1202).

105) BT-Dr. 16/3146, S. 21.

106) Es kann aber durchaus auf Hirnorganoide in ihrem derzeitigen Entwicklungsstadium Anwendung finden.

107) Gesetz über den Verkehr mit Arzneimitteln (Arzneimittelgesetz-AMG) i.d. F.d. Bekanntmachung v. 12.12.2005 (BGBl. I S. 3394), zuletzt geändert durch Art. 2 Abs. 1 des G. v. 25.6.2020 (BGBl. I S. 1474)

108) VO (EG) Nr. 1394/2007 des Europäischen Parlaments und des Rates v. 13.11.2007 über Arzneimittel für neuartige Therapien und zur Änderung der Richtlinie 2001/83/EG und der Verordnung (EG) Nr. 726/2004.

109) BT-Dr. 7/3060, S. 1, 43.

110) Gesetz zur Regelung der Gentechnik (Gentechnikgesetz GenTG) i.d.F.d. Bekanntmachung v. 16.12.1993 (BGB1. I S. 2066), zuletzt geändert durch Art. 95 d. VO v. 19.6.2020 (BGB1. I S. 1328).

111) BT-Dr. 16/6814, S. 10.

112) Vgl. oben Fn. 53.

113) Haier, Der Chirurg 2014, 918, 919; Spranger, NJW 2005, 1084, 1085.

114) BGH, NJW 1994, 127.

115) Spranger, NJW 2005, 1084, 1085

116) Zur Behandlung von Organoiden als Sachen vgl. Taupitz, MedR 2021, 410 ff., zur Einstufung als Handelsgut ebd., S. 412 f. 
sich entweder ein Bewusstsein oder jedenfalls die Anlagen für die Entwicklung eines Bewusstseins entwickeln.

1. Regelungen für die Entnahme des Ausgangsgewebes, die Weiterverarbeitung des Gewebes zu Hirnorganoiden und die Regeln für eine Forschung an oder Transplantation der entstehenden Hirnorganoide, jedenfalls soweit die Regelungen des TPG keine Anwendung finden.

2. Regelungen über einen abgestuften Schutz von Hirnorganoiden mit unterschiedlich stark entwickeltem Bewusstsein. Dabei muss der Schutz sich nicht auf das maximale Bewusstseinspotential der Entität beziehen, sondern kann mit fortschreitender Entwicklung zunehmen, im Ergebnis also ein und dieselbe Entität stärker schützen, wenn man ihr erlaubt, sich länger zu entwickeln.

3. Regelungen, die sicherstellen, dass Versuche mit Hirnorganoiden in Anlehnung an den 3R-Ansatz des Tierschutzrechts auf die notwendige Menge und das notwendige $\mathrm{Ma}$ beschränkt werden.

4. Regelungen, die eine funktionierende Überwachung der stattfindenden Forschung ermöglichen, nicht unähnlich der Register-, Anzeige- und Genehmigungsvorschriften des TPG, StZG und TierSchG.

5. Je nachdem, wie hochrangig die zu schützenden Rechtsgüter angesehen werden, könnte ein solches Gesetz entweder als echtes Nebenstrafrecht ausgestaltet sein oder aber die Nichteinhaltung der getroffenen Regelungen durch eine Art Annexstrafrecht sanktionieren.

Soweit ein solches Regelungswerk die Forschung und damit die Forschungsfreiheit (Art. 5 Abs. 3 Satz 1 GG) betrifft, müsste allerdings geklärt werden, welches Rechtsgut von Verfassungsrang in Bezug auf Hirnorganoide geschützt werden soll.

\section{Ausblick}

Die Gesetzgebung sollte nicht zu lange abwarten, sich über die Notwendigkeit einer solchen Regelung grundsätzlich Gedanken zu machen: Schon jetzt macht die Forschung auf dem Gebiet der Hirnorganoide Fortschritte, die regelmäßig bahnbrechende neue Erkenntnisse liefern. Dabei werden die oben besprochenen ethischen Probleme zunehmend auch in der Bevölkerung rezipiert und sind in der Lage, heftige Diskussionen auszulösen ${ }^{117}$. Um zu verhindern, dass sich die Gesetzgebung mit einem plötzlichen Erfolg der Forschung hinsichtlich eines Auftretens oder der Nachweisbarkeit von Bewusstsein und den damit verbundenen Problemen unvorbereitet konfrontiert und dann ggf. zu schnellen, nicht abschließend durchdachten politischen Kurzschlussreaktionen gezwungen sieht, welche das Forschungsfeld und alle damit verbundenen vielversprechenden Möglichkeiten auf Jahre beschädigen können ${ }^{118}$, sollten die Vorbereitungen für ein gut durchdachtes und funktionierendes Regelwerk schon jetzt getroffen werden. So kann auch der Wissenschaft Sicherheit gegeben werden, wenn sie sich ihrerseits überraschend mit tatsächlichen Anzeichen des Vorliegens eines Bewusstseins konfrontiert sieht ${ }^{119}$.

In der Zwischenzeit darf die Forschung an Hirnorganoiden aber nicht aufhören. Bislang sind die bestehenden Regeln und Gesetze für die Forschung mit menschlichem Gewebe ausreichend ${ }^{120}$. Sie muss die Augen offenhalten für jeden Hinweis auf die Ausbildung eines Bewusstseins. Tritt ein solches auf, sollten laufende Versuche, wenn möglich, unterbrochen werden, und eine Ethikkommission sollte in die Entscheidung über ein weiteres Verfahren eingebunden werden.

Die Forschung an Hirnorganoiden verspricht viele wertvolle Erkenntnisse sowohl in der Grundlagenforschung als auch für die therapeutische Anwendung. Ihr Fortschritt sollte daher nicht gefährdet werden, wie auch Madeleine Lancaster in einem Gespräch mit Nature ${ }^{121}$ hervorhebt: „There are truly conscious people out there with neurological disorders with no treatments. If we did stop all the research [...] that would be very detrimental to actual human beings who do need some new treatment."

117) Reardon, Nature 2020, 658

118) Man mag sich an den öffentlichen Aufschrei zurückerinnern, der der Ankündigung He Jiankuis im November 2018 folgte, dass er genomeditierte Säuglinge zur Geburt gebracht habe, in dessen Folge nicht nur eine Reihe hochrangiger internationaler Wissenschaftler ein Moratorium der Geneditierungsforschung am Menschen forderte (Lander/Baylis/Zhang u. a., Nature 2019, 165) sondern auch die WHO an Regierungen weltweit appellierte, solche Forschung in Zukunft zu unterbinden (https:// www.who.int/news/item/26-07-2019-statement-on-governance-and-oversight-of-human-genome-editing, Zugriff am 21.7.2021).

119) Vgl. Reardon, Nature 2020, 658, 660 unter Hinweis auf Vrselja/ Daniele/Silbereis u. a., Nature 2019, 336, die nach der Feststellung scheinbar koordinierter EEG-Aktivität in Schweinehirnen die Experimente zunächst pausiert haben, um die Meinung eines Ethikrats einzuholen und während des weiteren Verlaufs der Versuche die Schweinehirne vorsorglich anästhetisiert haben, um mögliches Bewusstsein zu unterbinden.

120) Dazu gehören auch berufsrechtliche Regelungen und standesrechtliche Regelungen, die ggf. von internationalen Berufsverbänden u.ä. Organisationen herausgegeben werden. Die Regelungen solcher Organisationen, exemplarisch der ISSCR, haben zwar keinen Gesetzescharakter, anders als nationale Gesetze finden sie aber international Anwendung und können so, ggf. sogar besser als nationale Gesetze, eine einheitliche Behandlung bestimmter Sachverhalte sicherstellen.

121) Reardon, Nature 2020, 658, 661. 